\title{
Study on Intensive Development of University Journal
}

\author{
Meiying $\mathrm{Wu}^{1, *}$
}

\author{
${ }^{1}$ Journal Editorial Department, City College of Dongguan University of Technology, Dongguan, Guangdong 523419, \\ China \\ *Corresponding author. Email: 619219260@qq.com
}

\begin{abstract}
Intensive publishing mode allows university journals to overcome the dilemma of "small, scattered and weak". However, such mode requires reform of traditional operation concepts, which can be realized through measures including strategic cooperation. Strategic cooperation refers to the construction of digital publishing platform online, the launch of rich work exchanges and academic seminars offline, and the establishment of intensive publishing mode integrating online and offline, thus realizing mutually reinforcing and co-construction and sharing of journal resources among university journals.
\end{abstract}

Keywords: university journals, strategic cooperation, intensification, publishing mode

\section{INTRODUCTION}

A century has elapsed since the birth of university journals in China, braving much hardship and fuelling the prosperity of academic journals and the universities. The deepening reform of higher education and academic journal publishing market has exposed the flaws of "small, scattered and weak" of university journals. How to better current situation, enhance its influence, drive innovation, and realize the transformation from "small, scattered and weak" to "big, concentrated and strong" is the issue to be solved facing university journals.

\section{THE PROPOSAL, IMPLEMENTATION AND DISCUSSION OF INTENSIVE PUBLISHING MODE OF UNIVERSITY JOURNALS}

\section{A. The proposal and discussion of intensive publishing mode of university journals}

"Intensification" is the management idea of boosting market competitiveness of enterprises by effectively integrating and optimizing the allocation of production resources. The West has witnessed mature intensification of journals. The fierce market competition makes several heavyweights in journal clusters stand out, such as Reed Elsevier Group PLC and Springer Group. The Western experience shows that intensification is the best choice to improve the comprehensive strength of single journal, which has been widely recognized among academic circles in

*Fund: This paper is the key platform and scientific research project of The Education Department of Guangdong Province in 2017 (2017WQNCX185); 2018 Editorial Research Project of Journal Research Society of Colleges and Universities in Guangdong Province (20180302); Dongguan Social Science Planning Project of 2019 (Project No.: 2019ZC27).
China. [1] [2] China has also achieved fruitful results in intensification, such as the establishment of periodical publishing groups including National Medical Journal of China [3], Beijing Prominion Publishing Co. Ltd [4], Journal of Materials [5], as well as journal clusters based on professional societies, industry associations and the same governing body, represented by Chinese Medical Association journal cluster [6], China optics journal cluster [7], resource and environment journal cluster [8], etc. Such research and practice provides experience and insight for the development of journals. [9]

As to university journals, intensive development was put forward as early as 1997, when Chen Yutang [10] and others held that university journals should follow the road of intensive management, joint publication, professional focused and subject-based publication. Subsequently, relevant discussions headline in several major journals. Peng Zhixiong [11], You Xingya [12], Wang Haifeng [13] elaborated on the possibility of collectivization development of university journals. According to Peng Zhixiong [11], the classification of journals was so poor that the favor from management organization is needed. The journal title should be changed from Journal of XX University to Journals of Chinese Universities: Literature. The pattern featuring special column and conglomeration should be followed. Wang Haifeng [13], however, disagree, pointing out flaw in issue, classification, management, operation and other aspects. Lin Feng [14] contributed his thoughts to the establishment of joint website of university journals in the province. Zhu Huijuan [15] proposed the establishment of strategic alliance, which is conducive to the formation of professional characteristics and facilitate the solicitation and review of papers. Ji Haitao, Guo Yumei and others [16] put forward virtual alliance, believing that 
collectivization reform involving the change of host unit, personnel ownership and other issues is not userfriendly. As a result, they proposed to establish virtual alliance while maintaining the independence of each journal. 2009 saw the establishment of Specialized Series of University Journals in China consisting of 21 famous journals by integrating and publishing digital resources, which is a positive exploration of virtual alliance. The practice of "entity" intensive management of university journals is usually based on the same governing body. For example, Periodicals Agency of Shanghai University has come to fruition after realizing intensive management. [17]

\section{B. Implementation and problems of intensive publishing mode of university journals}

An overview of the empirical research on intensification of academic journals in China reveals that only journals following collectivized management and journal clusters based on the same society, association or competent unit have succeeded. University journals belongs to the latter. This process is also a beneficial exploration of virtual alliance. In practice, the first is that units constituting the alliance are famous with certain academic influence. Besides, only publishing digital resources have been integrated, and no fundamental changes were made in publishing process. In addition to these well-known journals, most university journals are affiliated to average universities and higher vocational colleges, each of which has their own journals. Such journals are blamed for the issues of "small, scattered and weak" mentioned above. How to integrate the resources of university journals on the premise of keeping their independence and launch intensification with characteristics of university journals is worth thinking in the industry. Therefore, based on the reality of university journals, the author attempts to build a publishing mode featuring mutual independence and co-construction and sharing of publishing resources through strategic cooperation, so as to better the strength of university journals, and thus provide insight to solve existing difficulties.

\section{THE SIGNIFICANCE AND PRINCIPLE OF ESTABLISHING STRATEGIC COOPERATION AMONG UNIVERSITY JOURNALS}

\section{A. The significance of establishing strategic cooperation among university journals}

Strategic cooperation is an economic activity in which two or more parties achieve mutually complementary resource advantages and win-win cooperation based on the same goal. Neil Rackman argues that collaboration reduces duplication and waste, and creates new opportunities by leveraging each other's core capabilities to increase productivity and value added. [18] Different from collectivization development, the strategic cooperation between university journals is mainly realized through the negotiation, signing and implementation of strategic agreement to jointly build and share resources. Such move not only increases the strength of the single issue, reduces the cost of publication and duplication and waste, but also obtains the effect of "1+1>2". The coconstruction and sharing of publishing resources of university journals can be realized from the editorial department, integrating editorial board and editors, adjusting traditional and digital publishing channels, and sharing the latest publishing information. All elements of academic journal publishing, such as reviewers, authors, research platforms, academic information and readers, should also be integrated to give full play to the backing role of universities, thus doubling or multiplying editing and publishing strength. In addition, the co-construction of publishing platform can effectively lower waste of human, physical and financial resources caused by the repeated construction of website. Meanwhile, previous ideas such as the communication of university journals and the innovation of content construction [19] against media integration restricted by funds, manpower and other factors can be launched thanks to strategic cooperation, so as to enrich the content of journals, enhance the adhesion with potential authors, and expand the influence of journals.

\section{B. The principle of establishing strategic cooperation among university journals}

Neil Rackman [18] holds successful partnerships cannot be realized without contribution, intimacy, and vision. Contribution refers to the effective result that the partner can provide or create, such as increasing productivity, improving profitability, etc. It's the reason partnerships exist. Successful partnerships require equal contribution and sharing of results. Successful intimate relationships can trump transactional relationships. Intimacy can be measured from three dimensions: trust, information sharing and the team itself. Vision is the guidance system of cooperative relationship, the starting point and foundation of successful cooperation, providing direction guidance for its establishment, and justifying the risk and cost of cooperation. Based on the viewpoint of Neil Rackman and the reality of university journals, the author takes that successful strategic cooperative relations of university journals should follow certain principles.

The first is the principle of willingness, which is the premise of strategic partnership. As the saying goes, nothing forcibly done is going to be agreeable. Willingness requires both parties to reach the intention of mutual trust and co-construction and sharing of information resources after thorough communication. 
The second is the principle of equality, which is the basis for the establishment of strategic partnership and a condition for its stable and sustainable development. Equality includes two aspects: the equality of cooperation input and the equality of results sharing. As input of resources is swayed by strength of journals, both sides should enjoy equal or complementary competitiveness. In terms of the balance of power, the factors such as the level of journals and the strength of supervisor of sponsor unit can be taken into account. Mutual complementarity should be based on one's own needs. The journal enjoying sponsor unit with favorable academic resources but lacking funds for expansion should seek deep-pocketed partners. Equality in fruits sharing leads to win-win results and drives sustainable cooperation.

The final is the principle of compatibility, which is the key to strategic partnerships. First, both parties shall be compatible in terms of the purpose, objectives and positioning of the journal. For example, some journals follow the internal principle of manifesting teaching and scientific research within the university, which is less compatible compared with strategic cooperative mode characterized by open thinking. Therefore, university journals should change the traditional concept, advocate that of the new era, and promote the compatibility of the two parties in purpose and goal of running journals. Next, published content should be compatible. The compatibility of publishing content requires both parties to re-plan the characteristics and column setting, so as to achieve differentiated development and avoid the unhealthy competition phenomenon such as the scramble for manuscripts caused by same publishing content. Besides, the free flow of high-quality manuscripts within the scope of cooperation should be advocated. For example, when a manuscript is rejected, it can be recommended to a partner to prevent the drain of good manuscript. Lastly, regional compatibility. Regional compatibility can significantly reduce communication costs of both parties and highlight regional advantages. Therefore, it is suggested to seek regional partners in the initial stage of strategic cooperation.

\section{CONSTRUCTION OF INTENSIVE PUBLISHING MODE OF UNIVERSITY JOURNALS BASED ON STRATEGIC COOPERATION}

\section{A. Changing the concept of running journals and establishing that of the new era}

The traditional idea of school-based journals is that university journals are academic journals sponsored by universities, which mainly reflect teaching and scientific research of the university, serving its teaching and scientific research and the cultivation of academic talents. The paper studies the core issue of how to run university journal based on such traditional concept. The results show that the column setting is aimed to fully reflect the discipline construction of the university, and the manuscript standard is more in favor with authors of the university, which directly leads to its disorder, homogeneity and closure, thus undermining influence and academic quality. Therefore, the ultimate problem of whom to serve and how to serve should be reviewed again. As for whom to serve, considering that journals are sponsored by colleges and universities and the resources needed are provided by them, the author holds that they serve the colleges and universities where they are located. Secondly, as the publication disseminating advanced academic research achievements of related disciplines, the journal should serve for the academic development of the discipline. Thirdly, the journal disseminates the author's research results, thus affirming the author's academic contributions. The guidance on the writing and revision of academic papers is helpful to cultivate academic talents, indicating that journals serve the authors. Therefore, the journal serves the university, academic development and author. As for how to serve, the services needed by universities, academic development and authors should be clarified: what kind of journals can promote the development of universities, academic prosperity and the cultivation of authors. The traditional practice reflects the development of the school's disciplines and protects the interests of the school's authors, failing to realize its real function. In addition to formal service, colleges and universities need an influential journal to convey their strength or promote their development. Academic research results need more feedback from readers, and the author needs to master the essence of academic paper writing. Therefore, the three major service functions of the journal can be realized only by sharpening its strength, improving its academic influence and adhering to the fair peer review and feedback system.

Strategic cooperation refers to in-depth cooperation in all aspects of production and operation between all parties based on long-term win-win consideration. It is the premise of strategic cooperation for journals to change the traditional concept of running journals. The change of concept is helpful to correctly understand the current situation and existing problems of university journals, adopt an open way, reach strategic cooperation voluntarily, and then realize the compatibility of the purpose and content, thus ushering in strategic cooperation.

\section{B. Co-construction and sharing of digital publishing platforms of university journals based on strategic cooperation}

How to realize the synchronous sharing of resources is the first problem to be solved in the construction of 
strategic cooperative publishing model of university journals. The booming big data technology has accelerated the maturity of digital publishing platform construction for academic journals, which may bring the problem to an end. A digital publishing platform serves as a basket for digital information, where partners put their shared information and get needed information. The updating, maintenance and acquisition of information through baskets are the process of resource co-construction and sharing.
1) Construction and operation of digital publishing platform model for strategic cooperation of university journals: The construction of digital publishing platform based on strategic cooperation should take into account the issue: how to realize co-construction and sharing of resources while maintaining independence of each journal. The experience of existing digital publishing platform can be employed for reference [20] to build strategic cooperation digital publishing platform of university journals, which is composed of three modules: editing platform, production platform and publishing platform (see "Fig. 1").

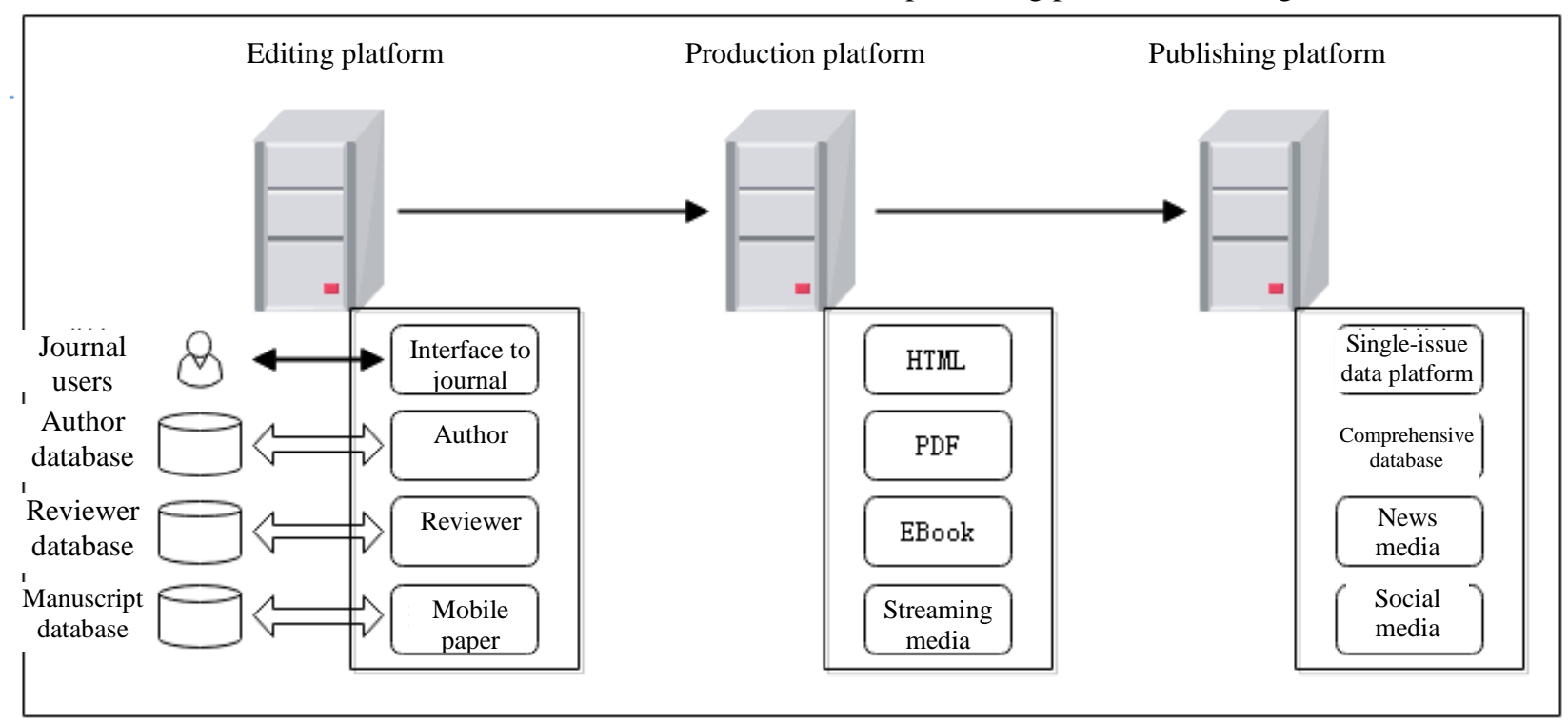

Fig. 1. Construction of digital publishing platform model for strategic cooperation of university journals.

a) Editing platform: The co-construction of editing platform is an important channel to realize the sharing of publishing resources among cooperative units. The platform boasts three repositories, namely, author database, reviewer database and mobile manuscript database. The author database records the data of all authors who have successfully registered on the platform. In order to expand the data volume, each cooperative unit should strengthen the publicity among original author group, reader group and the teachers in the school, thus increasing the registration volume. Thanks to the author database, each cooperative unit can receive the authors' contributions, as well as send contribution wanted, publishing trends and relevant academic activities to authors, enhancing the bond between the journal and the authors. In addition, after successful registration on the platform, authors can submit their articles to the affiliated journals of the platform, thus avoiding multiple registration. The reviewer database covers reviewers who have been invited by the partners or who have applied by themselves. The database contains basic information of reviewers, review direction, review quantity and review evaluation, etc., providing convenience for the selection. The reviewer receives the invitation through the manuscript review system and conducts peer review. The mobile manuscript database mainly stores manuscripts that have not been accepted. The contributions in this database can be checked by editors of other journals. If the contributions pass first round of review of a journal, the editors can send an invitation to the authors whether they agree to be resubmitted, and if the authors agree, they can be resubmitted to the journal. However, if the contribution does not pass the initial review by editors of each journal, the platform will issue a rejection notice. Such database, on the one hand, realizes the free flow of contributions in cooperative units and prevents the drain of high-quality ones. On the other hand, the acceptance rate of authors' submissions also increased.

b) Production platform: Contributions that are accepted through peer review are incorporated into 
production platform and produced into various documents such as HTML, PDF, eBook, and streaming media as required for publication. HTML files can be read by a variety of web browsers, which is convenient and fast. PDF files feature integration, security and reliability, which can be published and distributed through multimedia. EBook is a new online publishing method created by Internet technology, which mimics the traditional way of publishing and distribution books. Streaming media is compatible with different terminals, with automatic line wrapping, font size adjustment, retrieval in PC terminal. Each format has its advantages. The production of these document cannot be separated from staff with professional knowledge and skills, which increases publication cost of each cooperative unit. The strategic cooperation has realized the sharing of resources, and the work can be handled by a special person of a cooperative unit, or by a professional third party.

c) Publishing platform: According to the construction experience of intensive publishing platforms of academic journals inside and outside China, publishing platforms of university journals in the context of strategic cooperation consist of four modules, namely, single-issue data publishing platform, comprehensive database, news media and social media. The single-issue data publishing platform mainly publishes the content of single issue. Readers can browse the publication data of each issue, the latest data about acceptance and other information on this homepage. Comprehensive database integrates publication data of various journals. Big data technology can also be employed here to extract metadata for analysis, and data mining and other technologies can be applied to generate multiple academic research tools for researchers, thus bettering data service of the platform. Strategic cooperation featuring resource integration could be adopted by news media to release the latest publishing information, academic research information, academic activity preview and report of each cooperative unit and its university, in a bid to create a strong academic atmosphere, improve its image, and attract more excellent manuscripts. Social media mainly coordinates the network publishing platform with WeChat, weibo, QQ and other social media to facilitate the reception, reading and even processing of published data by readers, authors, reviewers and editors.

2) Construction of publishing platform and solutions to operation and maintenance issues: Construction of publishing platform of university journals against strategic cooperation should take the actual situation of cooperative units into full consideration and try to satisfy each unit. In addition, the clarification of rights and responsibilities of all parties in coordinating operation and maintenance and construction of the publishing platform are equally important, which sways actual implementation. To solve this problem, it is necessary to set up a working group of publishing platform construction, which is responsible for the construction of the platform, the supervision of construction process and operation and maintenance. The construction of the platform shall be jointly funded by the partners, and a third party shall be selected to carry out the operation and maintenance in the process of construction and use. The work involving professional technical projects in the use process, such as production, publishing metadata extraction and data mining analysis, can be assigned to a specific cooperative unit or a professional third party. The cost for either scheme shall be shared by the partners to ensure the smooth construction, operation and maintenance of the publishing platform.

\section{Carrying out rich offline publishing work exchanges and academic seminars}

The construction of strategic cooperative publishing platform makes the online co-construction and sharing of publishing resources of university journals come true. Close partnership, in addition to online resource cooperation, also requires offline publishing work exchange. Partnerships can be strengthened then to make them more reliable. What's more, the communication of publishing work can coordinate the publishing work, unify the pace, give play to the intellectual advantage, as well as improve the professional quality of editorial staff through peer communication. Therefore, the cooperative units should regularly hold one or two plenary work seminars every year to summarize the situation of the previous period, analyze the achievements, discover existing problems and discuss solutions. The meeting can also be employed to discuss key topics and projects for the coming year and evaluate the work of the journals. Other business communication activities shall also be held from time to time according to work needs.

In order to expand the influence, university journals should play an active role in promoting and guiding academic research. An academic seminar is also a helper. University journals participated in strategic cooperation no longer fight alone, backing by all partners and their host universities. The growing strength supports the launch of academic seminar by university journals. Seminars can be of various types and scales. For example, small public webinar planned by the publishing platform, or offline professional seminar held by universities. Professional researchers and other researchers of the cooperative unit are invited to participate. Editors of other cooperative units may also act as co-organizers to reduce the work burden of 
the host unit. Academic conference can not only enhance the influence of the journal, but also attract more contributions, realizing win-win outcome.

\section{MEASURES OF INTENSIVE PUBLISHING MODE OF UNIVERSITY JOURNALS BASED ON STRATEGIC COOPERATION}

The following measures are proposed to improve the practicality of strategic cooperative publishing mode of university journals. The first is to sign a formal strategic cooperation agreement. The signing of strategic cooperation agreement makes the cooperative relationship subject to legal constraints and protection, guaranteeing the launch of cooperative projects. In case of differences of opinion or other circumstances during the cooperation, the agreement may also protect the interests of all parties in accordance with the law. The next is the establishment of leading body for strategic cooperation, and the division of labor based on actual situation, thus strengthening communication. Then, special fund for strategic cooperation projects shall be set up and detailed rules for its use shall be formulated to strengthen effective supervision and ensure its proper use and implementation. The special fund may be paid by the cooperative unit in accordance with the agreement, or it may be the special construction fund applied to the state. The fund can be consumed for common financial expenditure projects, such as the construction, operation and maintenance of the abovementioned publishing platform, which requires a large amount of capital input. The last is to deal with the withdrawal of cooperative units and the admission of new units. The substantive assets arising from the construction of strategic cooperation projects, such as the completed publishing platform, shall be completed jointly during the cooperation period, and each cooperative unit shall have the ownership of the platform. In order not to affect the cooperation relationship between other parties, the normal development of relevant work, and protect the rights and interests of the quitting party, the quitting party can obtain the source data of the platform construction for future independent development and use on this basis. If a new unit applies for joining, factors such as the upfront investment cost shall be taken into account, and an agreement on joining shall be reached after thorough communication. Various measures should be implemented to ensure the operability of strategic cooperative publishing mode, which offers new insight for university journals facing same dilemma.

\section{CONCLUSION}

The deepening reform of academic journals in China calls for reform of university journals. Among the various schemes to make university journals get rid of the dilemma of "small, scattered and weak" and complete the transformation to "big, concentrated and strong", strategic cooperation merits mention. Based on the features of university journals, this paper makes it clear that changing their traditional concept is the first and foremost for strategic cooperation, and puts forward that strategic partnership of university journals should follow the principles of willingness, equality and compatibility. On this basis, the construction of publishing mode integrating online and offline resource cooperation among university journals is proposed to start further discussion.

\section{References}

[1] Wang Xiuling, Liu Pu. The development and countermeasure of the intensive management of academic journals in China $[\mathrm{J}]$. Chinese Journal of Scientific and Technical Periodicals, 2016,27(12):1253-1258. (in Chinese)

[2] Sun Fayou, Li Tiechui. Analysis of the lack of motivation for intensive management of academic journals [J]. A Vast View on Publishing, 2012(07):54-55. (in Chinese)

[3] Jiang Yongmao, Liu Bing, et al. Construction and development ideas of the journal group of the Chinese Medical Association [J]. Chinese Journal of Scientific and Technical Periodicals, 2014, 25(6): 740-743. (in Chinese)

[4] Fan Yameng, Liu Guozheng. The integrated development and intensive management of academic journals-the developmen trend of academic journals under media integration [J]. Chinese Journal of Scientific and Technical Periodicals, 2017, 28 (4) 340-343. (in Chinese)

[5] Chi Mei, Liu Dong, Zhou Haiyan, et al. Practical exploration and development thinking on intensive publication of material journal office $[\mathrm{J}]$. Chinese Journal of Scientific and Technical Periodicals, 2017, 28(9):793-798. (in Chinese)

[6] Li Hui, Ma Jianhua. A case study on the intensive operation of journals of the China Association for Science and Technology - Taking the Chinese Medical Association as an example [J] Chinese Journal of Scientific and Technical Periodicals, 2011, 22(6): 860-862. (in Chinese)

[7] Chi Xiuli, Hou Chunmei, He Haoyu. Professional clustered online publishing platforms of sci-tech periodicals in China $[\mathrm{J}]$ Acta Editologica, 2015, 27(2): 182-185. (in Chinese)

[8] Yang Xiaomei, Chi Xiuli, Hou Chunmei, et al. Sustainable development strategy of the clustered journals of resources and environment sciences under the media convergence background [J]. Acta Editologica, 2018, 30(1): 66-69. (in Chinese)

[9] Huang Hongmin, Ma Aifang, Zhang Jing. Current status of professional clustered online publishing of science and technology journals in China [J]. Chinese Journal of Scientific and Technical Periodicals, 2013, 24(2): 238-241. (in Chinese)

[10] Chen Yutang, Wang Shimin, Zhang Jun, et al. Intensive management, joint publication of journals, centralized professional publishing by disciplines-Reflections on the reform of university journals [J]. Chinese Journal of Scientific and Technical Periodicals, 1997,8(1)33-35. (in Chinese)

[11] Peng Zhixiong. Conception of Collectivization of University Journals [J]. Editors Friend, 2010(2):55-56. (in Chinese)

[12] You Xingya. Thoughts on the Group Development Model of University Journals [J]. Editors Friend, 2010(4):57-58. (in Chinese)

[13] Wang Haifeng. Argument on the Collectivization and Regional Development of University Journals [J]. Editors Friend, 2011(2):82-83. (in Chinese) 
[14] Lin Feng. Discussion on Establishing a Joint Website of Provincial University Journals [J]. Editors Friend, 2010(12):4750. (in Chinese)

[15] Zhu Huijuan. Thinking about building strategic alliance among university journals [J]. Acta Editologica, 2004, 16(2): 121-122. (in Chinese)

[16] Ji Haitao, Guo Yumei, Guo Xiaoliang. Virtual Alliance: The Group Development of University Journals [J]. Chinese Journal of Scientific and Technical Periodicals, 2012, 24(1): 54-56. (in Chinese)

[17] Qin Na. Intensification boosts the management innovation and development of sci-tech journals - Taking Periodicals Agency of Shanghai University as an example [J]. Chinese Journal of Scientific and Technical Periodicals, 2014, 25(6):744-747. (in Chinese)

[18] Neil Rackman. Getting Partnering Right [M]. 1 Edition. translated by Su Yizhong. Beijing: Economic Management Publishing House, 1998: 46-59. (in Chinese)

[19] Wu Meiying. Exploration of the content construction of academic journals under the background of media integration [J]. A Vast View on Publishing, 2018(12): 49-51. (in Chinese)

[20] Mao Zhengang, Liu Suqin, Zhang Litian. The status quo of international OA publishing platforms and suggestions on the publishing model of "Internet + academic journals" [J]. Acta Editologica, 2017, 29(03):299-303. (in Chinese) 